\title{
HCI Requirements for Young Primary School CALL Learners
}

\author{
Monica Ward \\ School of Computing, Dublin City University, Ireland \\ Monica.Wardecomputing.dcu.ie
}

\begin{abstract}
This paper looks at the HCI requirements of young learners in the context of Computer Assisted Language Learning (CALL) resources. It explains the motivation behind the project and the specific deployment context. It outlines some key components that must be taken into account when developing materials for this learner group. For example, the learners cannot read, so no text can be used on the screen. Colors and images are very important to make the material attractive and intuitive for the users. It shows that using HCI observations from other researchers, along with a structured approach, combined with an agile paradigm can produce useful, usable CALL resources in a limited resource context.
\end{abstract}

Keywords: young learners, HCI, CALL, primary school, agile paradigm.

\section{Introduction}

This paper looks at the Computer Assisted Language Learning (CALL) HCI requirements for young primary school learners. It outlines the deployment context of the CALL resources and the particular HCI considerations that have to be taken into account when developing resources for young learners. Young learners differ from adult learners in several respects and psychology, art, design, physiology and ergonomics must be taken into account when considering their HCI requirements.

From a psychological point of view it is important to understand the learners and their requirements, in order to design suitable CALL resources for them. Designing and developing CALL resources for any user group must include analysis, design, development, testing, and implementation stages [1]. The analysis phase for this project was carried out in conjunction by the class teacher and it was determined that there was a learner need and that it was feasible to build CALL resources for the learners. In this scenario, the pedagogical design was driven by the teacher, who wanted CALL resources that were aligned with her classroom teaching. The lack of integration of CALL resources with classroom activities is one of the reasons why CALL resources are not as successful as they should be in the primary school context [2].

Obviously, the User Interface (UI) has to take into account the preferred aesthetics of the target users (which may differ from adult learners). For example, colors, font size, buttons, text (or no text) are some areas of difference with adult learners. An 
agile software development paradigm was used in the development of the CALL resources for a number of reasons. An agile paradigm is useful when dealing with an unfamiliar context, so it was useful in this project. Young learners have a different physiology than adult learners and this too must be taken into consideration when design CALL resources for them. Also, ergonomics are just as important for young learners as they are for adult learners, although sometimes there is limited scope to change the ergonomics of the deployment context. Testing is a key part of any software development and it was important to carry out both formative and summative testing as part of the project. The implementation phase of the project involved first training the learners with the resources and then letting them use them at their own pace.

This paper provides an overview of the project from a HCI perspective, and outlines what worked in this context and provides some suggestions for future projects in this domain.

\section{Background}

\subsection{Motivation and Deployment Context}

In Ireland, most children start primary school at 4 or 5 years of age. The first year of primary school is called Junior Infants. Children study a range of subjects, including English, which is one of the national languages, along with Irish. In Junior Infants the children learn the alphabet in synthetic phonetic form. The aim of this project was to develop English spelling resources that would allow the students to practise what they learnt in class, at their own pace and to repeat exercises as often as they wanted. The CALL resources would also enable the teacher to monitor the progress of each student. Currently, it is difficult for the teacher to monitor each student individually in real-time. Sometimes it can be difficult for her to see how quickly and effectively each individual student is mastering the material. One of the aims of the CALL resources was to provide a tool for the teacher to see what each student was able to do and what presented difficulties. The teacher would be able to see at a glance, in realtime, what each student was doing, as well as the class overall.

In 2010, the government introduced a free pre-school year for children. This means that most children have attended an authorised pre-school before starting primary school and they can recognise letters and sounds to some extent on entry into primary school. This aims to ease the transition from pre-school to primary school for the children. In Ireland, schools in or close to cities, the schools may be single sex schools, but outside of these areas, the schools are mixed. The school in this study is a boys' school and there were 24 boys in the class. In order to comply with Ethics guidelines, the boys' parents were asked to sign a consent form. Not all parents signed the form, perhaps due to loosing it rather than any objections so data usage statistics were recorded for 17 boys. However, all boys got a chance to use the system.

The school has a computer room with 19 PCs, of which only 16 worked. The PCs were rather old, and had older monitors that took up a lot of space. The keyboard just 
about managed to fit on the table and space was very limited. The students had one 30 minute session in the computer lab per week. The students were reasonably competent computer users (e.g. they were familiar with the keyboard and mouse, and know how to click on icons). Young primary school CALL learners are only beginning to learn to read and write in their first language (L1). Therefore, when developing CALL resources for this target learner group, there can be no written instructions and this presents special. Furthermore, the look and feel of the CALL resources has to be clear and appealing to the students, as well as being pedagogically appropriate.

This paper looks at the HCI requirements of Junior Infant students (i.e. 4-5 year old pupils at the Preoperational stage of development [3] in a primary school in Ireland. Often the students had to share a PC with another student, and while this has HCI implications also, the focus of this paper in on the design of the CALL resources in particular (see [4] for HCI with children). This school would be fairly typical in Ireland in terms of computing resources, teacher computer literacy, class size and student ability.

\subsection{CALL Resource Overview}

The teacher wanted CALL resources that would enable the students to reinforce their prior learning and allow them to test themselves with regards to spelling words. There were four exercise types developed for this purpose. The easiest exercise for the students was the matching exercise, in which the student was shown three different images and had to match the correct word with the correct image. The next easiest exercise was the mixed-up word exercise, in which the students where shown the letters of the word jumbled up and had to spell the word correctly. The final two exercises were cloze exercises, in which the students had to spell the word. In the first of the cloze exercises (single cloze), the students just had to spell one word, while in the other cloze exercise (the multi-cloze exercise) they had to spell three words. Students worked on a different set of words each week, and this set was closely aligned with what they had studied the previous week in class. For example, "pin, sit, pat, tap" was one group of words that was used at the start of the project.

Students could check their progress through the exercises by clicking on a progress button and it would show them how many gold star they had and how many more they needed to get to complete all the exercises. There were several analysis features available to the teacher. The most important one was the real-time student progress monitor. This showed who was logged in, what exercises they had attempted and how successful they were at those exercises. This enabled the teacher to check that the lesson was proceeding more or less as planned.

\section{Planning, Analysis and Design}

Planning and design are key phases in the genesis of any software project [5], including CALL resources. Planning determines if the project will go ahead, if the 
project is feasible and defines the scope of the project. Analysis works out what the project requirements are and what the will be the scope of the project. [1] has designed a very use grid (Global-Local-Differential-Targeted) that takes into account the main 'players' in the learning process (learners, teachers, pedagogy, technology, content and other actors (e.g. society)).

HCI design must take into account including what the users want and expect and what users find enjoyable and attractive [2]. A user-centred approach [7] was adopted in which the teacher was consulted regularly during the planning, design and development stages of the project - this is especially important when the CALL developer may be unfamiliar with the needs and abilities of the target learner group. The key is to keep it simple and avoid functionality creep [8]. Learners had mainly a user role in the design process [9], but as an agile software development paradigm [10] was used throughout the project they also had a testing role.

\section{HCI Design}

The young learners in this project were only starting to learn the letters of the alphabet and could not yet read (apart from a few very simple words). The need to avoid written instructions of any kind, including names on buttons, might seem trivial, but it is quite challenging. It means that images, colors and UI design must be intuitive and clear. The learners have to be able to navigate their way through the resources, with minimal teacher interaction. The images used in the resources need to be clear and non-confusing. Sometimes, it can be difficult to find suitable images, especially ones that work with older monitors and are age-appropriate. This section provides an overview of the considerations given to colors, images and other HCI features in the project.

\subsection{Colors}

Colors and coloring are very important when designing computer resources for children, especially when no written instructions are used. Children have positive reactions to bright colors [11]. For this reason bright colors were used for each different exercise type. Light purple was used for the mixed-up word exercise, yellow was used for the matching exercise, light green was used for the single word cloze exercise and cyan was used for the 3-word cloze exercise. It was important that the colors were bright, attractive and sufficiently different in order for the children to be able to distinguish between them. The school involved in this project is an all-boys school and this had to be taken into account when considering suitable colours for the different components of the CALL resources. For example, the boys associate pink with being a girls' color and would not be favourably disposed to seeing it on any of the exercises. 


\subsection{Images}

Images were central for the CALL resources. One of the most important concepts of the CALL resources was that the children could use the resources on their own, without the teacher working with them. This would allow them to work through the exercises at their own pace. This is very important in the Junior Infant class, as indeed other primary school classes, as there will be quite a range of abilities within the student group, and it can be difficult for the teacher to make sure that all students are working to their ability. As no written words could be used, in order to be able to spell a word, the students needed to see an image of the word. This meant that only words that could have an easily identifiable image were chosen for the exercises (generally nouns, but sometimes verbs and adjectives). The images had to be childappropriate. For this reason, cartoon images were generally used, as not only did they appeal to the students, but they tended to have brighter colors and appeared clearer on the screen.

Not only were images needed to depict the exercise words, images were also required for the buttons of the application. Images were needed for standard button types such as 'home', 'go back', 'next' and 'correct'. Furthermore, images were also needed to indicate 'correct' or 'incorrect' to the students, and colourful cartoon faces were used for this purpose (yellow, smiling face for correct, blue, unhappy face for incorrect).

\subsection{Other HCI Issues}

Design consistency is very important ([6], [12], [13]). In this scenario, it was especially important as there were no written instructions and it would not be possible for the teacher to spend time with each student individually in the lab to explain how each exercise worked. Each different exercise had to have the same look and feel as the others. The same buttons had to be in the same place and have the same functionality. This contributes to easy of learning, remembering and use.

Other design issues included avoid drag-and-drop interaction, as this can often be problematic for young children [14]. In the mixed-up exercise, there were two possible options for allowing the students to rearrange the jumbled up letters. One was to allow them to select a letter and drag it to the spelling line. The other option was to allow them to click on the letter and the system would automatically place it in the spelling line for them. Both options were testing with young learners and the drag and drop option proved problematic (as more manual/mouse dexterity is required for this movement). The learners can check if their answer is correct by clicking on the check button and they see a happy face if the answer is correct and an unhappy face if it is incorrect. However, sometimes the students would forget what they had done or would want to see how they were progressing and allowing learners to view their progress [15]. Fig. 1 shows an example of a cloze exercise (for the word pin). 


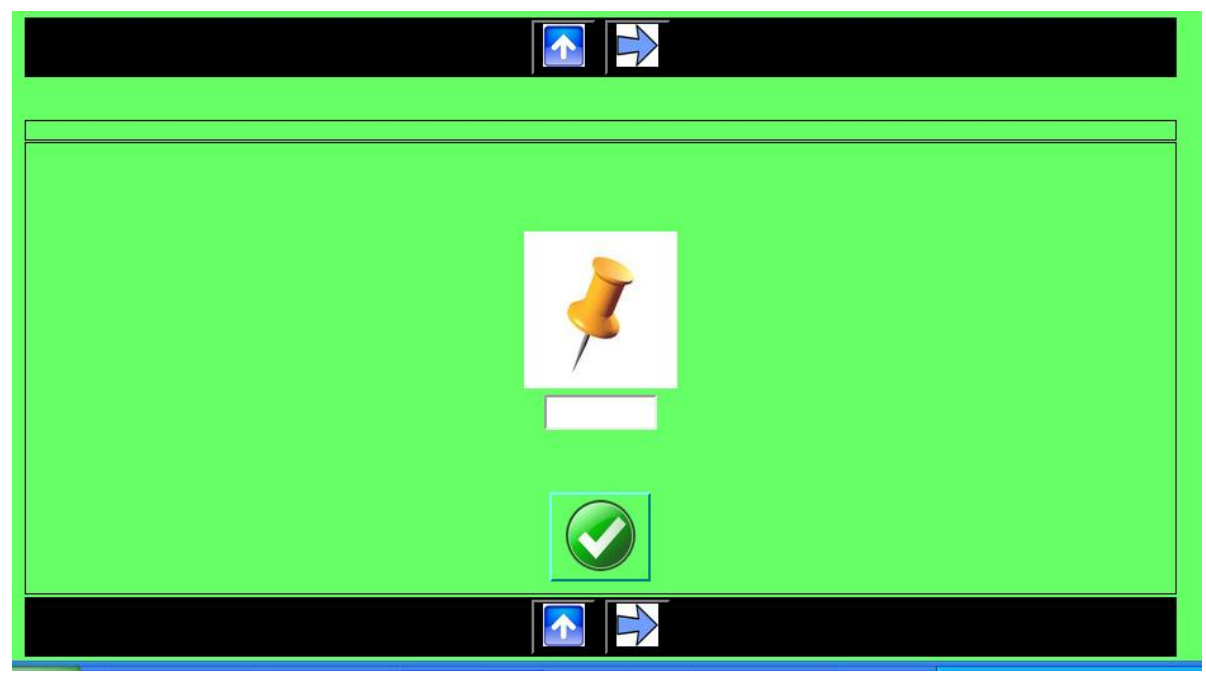

Fig. 1. Example of mixed up exercise (pin)

\section{$5 \quad$ Development and Testing}

\subsection{Development}

One important consideration in this project was the desire to have a relatively short turn-around time for the actual development of the CALL resources. There had been some discussion with the class teacher for several years about the possibility of developing suitable resources, but for a variety of reasons there was no progress beyond the discussion stage. From the start of this project, there was a determination that working CALL resources would be developed and deployed during the primary school year. This meant that existing resources would be reused to speed up the actual development process. In this regard, Hot Potatoes CALL authoring software was reversed engineered to provide a template for the generation of English spelling exercises. This facilitated the speedy and flexible generation of language exercises on a week-by-week basis. Also, in order to make sure that the students were able to use working parts of the software, even if the full suite of resources was not complete, an agile software development paradigm was adopted. The agile software development paradigm focuses on iterative and incremental development. In the case of this project, it meant that the students could use the basic version of the software and avail of new features as they became available (typically on a weekly basis). The CALL developer, the teacher and the students were learning throughout the project and modifications could be made very quickly if an error was detected or a potential enhancement identified.

For example, it became apparent that some of the images were not as clear as they should have been. Some mechanism was required to make it obvious to the learner what the word was. It was decided to add an audio component to the system, so that 
the students could hear the word being spoken, as well seeing a suitable image. Due to the agile approach, it was not that difficult to add this feature and have it ready for the following week.

\subsection{Testing}

While testing with the target learner group is important in the design and development of any CALL resource [11], it is particularly important when working with a learner group that is very distinct from a more familiar learner group [4]. Testing can reveal that the 'obvious' may not be that obvious to the target learners. Also, target learners can point out things that may be missed by the designer. It is really important to check out the suitability and feasibility of CALL resources with someone from the target learner group before real-world deployment, especially when a non-successful initial encounter with the CALL resources may inhibit future use of the resources. [16] and [17] provide guidelines and insights for testing with young learners which were useful during this phase.

As part of the testing process of this project, several young learners took part in the testing of the CALL resources. They were given minimal guidance in how to use the materials and were asked to use the system. Their interaction with the system was observed and important points were noted. They tried both the drag-and-drop and click versions in the mixed-up exercises, and, as expected (see [14], there were some difficulties with the drag-and-drop interaction. Therefore, as mentioned previously, the click option was adopted in the final version of the system. The young learners also helped out in choosing the images for some words. Several different images were shown to the learners and they picked the 'best' or their favourite one. The learners tested all parts of the system to make sure it was usable and worked as expected.

The other target user, i.e. the teacher, also had a chance to test the system. She tested the learners' part of the system as well as the teacher component. The teacher testing component was less extensive, due to the limited functionality of that part of the system, and the fact hat the teacher was a competent adult that could test the system fairly quickly.

\section{$6 \quad$ Training and Implementation}

\subsection{Training}

Providing training to the learners is a key component of successful CALL deployment [18]. If suitable training is not provided, the learners may not know how to use the system or may not be able to exploit it to it is full potential. Training is often overlooked, but it is important. It does not have to be long or overly complicated, especially if the system is well-designed, but it is important to give it sufficient consideration when rolling-out a system. One extra consideration in this particular scenario is that there could be no written instructions or help information for the learners as they could not read. Normally, a user guide or help facility would be 
provided with CALL resources. This guide would give an overview of the material and instructions on how to use the system. However, as a written guide was not an option, it was really important that the learners were trained on the system. In fact, the importance of making the user interface intuitive for the learners was a key consideration at the design stage of the product.

Therefore, the CALL resources had to be easy to use, easy to learn and easy to remember. The learners were shown how to use the CALL resources and were able to use them without too many problems - colour coding the components helped greatly in this regard. During the training process, an Interactive White Board (IWB) was used to show the learners how to use the system. They were shown step-by-step each different exercise and then given a chance to try it out for themselves. The learners had no particular difficulties in using the CALL materials.

\subsection{Implementation}

The students had access to the computer lab once a week for 30 minutes. Sometimes the teacher used this lab session to work on maths resources or other educational games with the students. For the duration of the project, the students worked on the CALL resources during their allocated computer time. This meant that there was an onus on the CALL developer to produce useful and educationally valuable software for the students if they were going to use their scare computer time on the CALL resources. Due to the fact that there were 24 children in the class and only 16 working computers, the children often had to share a PC. This meant that one boy logged in and his partner worked with him on the exercises. This impacted negatively the monitoring feature of the CALL software as the scores and usage of the system may not have reflected the ability of the logged in user (as he may have been assisted by his partner).

\section{$7 \quad$ Discussion}

There were several lessons learnt from this real-world deployment of CALL resources for young primary school learners. It is possible to design and develop clear, colourful, easy to use CALL resources using a modified authoring tool for this target learning group. It is important to use a user-centred design approach that includes input from the teacher and someone from the target learner group itself. It can be difficult to find suitable, unambiguous, age-appropriate images and persistence may be required when seeking out images. One helpful addition is the use of sound, which can help disambiguate images and make it clear to the learner what the image contains. While learners in the target group may have similar characteristics, there should be room for variation and customisation, and this would be one recommendation for future CALL projects in this area. For example, one of the students did not like the image shown for an incorrect answer (sad, blue face) and would cover his eyes if it showed up. In fact, this was a good student and generally the sad face only appeared when his partner was doing the exercises. In this situation, 
it would be good if the images could be customised for each student. It would add to the complexity, but could be feasible.

The CALL resources would also benefit from additional audio features. Initially, there were no audio features as it felt that it would not be feasible in the lab where one student would be able to hear the word being spoken, while his partner could not. However, in practice, this was not an issue as the boys were used to sharing headphones and would let their partner hear the word as well. In the light of this fact, it would be nice to add an audio feature to the progress monitoring screen that would play different music based on the learner's progress to date.

While this project was a success in terms of providing the teacher and students with curriculum aligned CALL software that they could actually used, there are still areas for improvement. Some of them are pedagogical related. For example, students learn 'sh' as a single sound e.g. 'shell'. In the mixed up exercise, the 'sh' can be shown as one unit, and the students are fine with that. When they have to actually spell the word, they have to type the letter 's' and then the letter ' $h$ ' and this can cause confusion. There are other issues related to the lack of computers available in the lab and one possible workaround for this is for some students to work on the same exercises printed on paper, while they wait their turn for a computer.

The issue of evaluation is a difficult one in the CALL context. There was no attempt in this project to compare this group of students with a peer (control) class, as there are so many reasons why this would not be feasible. The determination of success of the project was determined by the teacher and the students. Their qualitative feedback showed that they liked the system, that they found it easy to use and had not major suggestions for improvements. This feedback has to be tempered with the knowledge that children in this age group tend to want to please adults and that they may find it difficult to express their feelings [16]. However, informal interaction with the boys revealed that they did actually enjoy using the resources and kept asking me for more the next year. The teacher was happy with the CALL resources and felt that it did what she wanted it to do and that it was of value to her students.

\section{Conclusion}

In summary, this paper discusses how a CALL authoring tool was adapted and customised to the needs of this learner group. Some specific HCI considerations for the target group include using bright colors and 'obvious' images for buttons as no text could be used. The manual/mouse dexterity of the learners must be taken into account, so that their effort is focused on answer the exercises and not the actual process of system input. This paper reports on the deployment of these young learner oriented HCI CALL resources and the lessons learnt in the process. It shows that it is possible to produce and deploy useful materials in a relatively short space of time and with very limited resources. Some suggestions for future research in this area include the enhanced customisation and audio features, which could make the materials more attractive and assessable to the learners. The UI in this project looks very simple, because it is very simple. However, simple is not a bad thing and in this case it was exactly what was required and it as what worked. 


\section{References}

1. Colpaert, J.: Design of online interactive language courseware: conceptualization, specification and prototyping: research into the impact of linguistic-didactic functionality on software architecture. PhD diss., Universiteit Antwerpen (2004)

2. Ward, M.: The Integration of CL Resources in CALL for Irish in the Primary School Context. PhD diss., Dublin City University, School of Computing (2007)

3. Piaget, J.: Science of Education and the Psychology of the Child. Orion Press, New York (1970)

4. Bruckman, A., Bandlow, A., Forte, A.: HCI for kids. The human-computer interaction handbook: Fundamentals, evolving Technologies, and emerging applications, 428-440 (2002)

5. Sommerville, I.: Software Engineering, 9th edn. International computer science series. Addison-Wesley, Harlow (2010)

6. Galitz, W.O.: The essential guide to user interface design: an introduction to GUI design principles and techniques. Wiley.com (2007)

7. Abras, C., Maloney-Krichmar, D., Preece, J.: User-centered design. In: Bainbridge, W. (ed.) Encyclopedia of Human-Computer Interaction, vol. 37(4), pp. 445-456. Sage Publications, Thousand Oaks (2004)

8. Resnick, M., Silverman, B.: Some reflections on designing construction kits for kids. In: Proceedings of the Conference on Interaction Design and Children. Boulder, CO, pp. 117-122 (2005)

9. Druin, A.: The role of children in the design of new technology. Behaviour \& Information Technology 21(1), 1-25 (2002)

10. Martin, R.C.: Agile software development: principles, patterns, and practices. Prentice Hall PTR (2003)

11. Boyatzis, C.J., Reenu Varghese, R.: Children's emotional associations with colors. The Journal of Genetic Psycholog 155(1), 77-85 (1994)

12. Ozok, A., Salvendy, G.: Twenty guidelines for the design of Web-based interfaces with consistent language. Computers in Human Behavior 20(2), 149-161 (2004)

13. Koyani, S.J., Bailey, R.W., Nall, J.R.: Research-Based Web Design \& Usability Guidelines. National Institutes of Health (2003)

14. Inkpen, K.M.: Drag-and-drop versus point-and-click mouse interaction styles for children. ACM Transactions on Computer-Human Interaction (TOCHI) 8(1), 1-33 (2001)

15. Butler, Y.G., Lee, J.: The effects of self-assessment among young learners of English. Language Testing 27(1), 5-31 (2010)

16. Hanna, L., Risden, K., Alexander, K.: Guidelines for usability testing with children. Interactions 4(5), 9-14 (1997)

17. Donker, A., Reitsma, P.: Usability testing with young children. In: Proceedings of the Conference on Interaction Design and Children, College Park, MD, pp. $43-48$ (2004)

18. Hubbard, P.: Learner training for effective use of CALL. In: New Perspectives on CALL for Second Language Classrooms, pp. 45-68 (2004) 